\title{
Polymerization of Sulfur-Containing Aldehydes. I. Polymerization by Cationic Catalysts
}

\author{
Noboru Yamamoto and Iwao Yamashita \\ Government Industrial Research Institute, Osaka \\ Midorigaoka 1, Ikeda, Osaka, Japan.
}

(Received January 10, 1972)

\begin{abstract}
An attempt was made to polymerize sulfur-containing aldehydes such as $\beta$-methylthiopropaldehyde(MTPA), $\beta$-ethylthiopropaldehyde(ETPA), $\beta$-methylthiobutyraldehyde(MTBA), $\beta$-ethylthiobutyraldehyde(ETBA), and $\beta$-phenylthiobutyraldehyde (PTBA) using various cationic catalysts.

Poly(phosphoric acid), poly(phosphoric acid) aniline salt, and $\mathrm{BF}_{3} \mathrm{OEt}_{2}$ gave only a cyclic trimer in the different polymerization conditions. On the other hand, these aldehydes were polymerized by $\mathrm{SnCl}_{4}$ and by $\mathrm{AlBr}_{3}$ to the linear polyacetal and the cyclic trimer. The ratio of the polymer and the cyclic trimer produced was influenced by monomer structure, catalyst, solvent, and polymerization temperature. PolyETPA and PolyETBA were soluble in ethyl ether, tetrahydrofuran, and halogenized hydrocarbon, while polyMTPA and polyPTBA were partly insoluble in usual organic solvents.

KEY WORDS Polyaldehyde / Cationic Polymerization / Poly $(\beta-$ methylthiopropaldehyde) / Poly( $\beta$-ethylthiopropaldehyde) / Poly $(\beta-$ methylthiobutyraldehyde) / Poly( $\beta$-ethylthiobutyraldehyde $) / \operatorname{Poly}(\beta-$ phenylthiobutyraldehyde) / Substituted Trioxane /
\end{abstract}

Since the first reports on polymerization of higher aldehydes with catalysts were published by Vogl, ${ }^{1}$ by Furukawa, et al., ${ }^{2}$ and by Natta, et al. ${ }^{3}$ independently, a number of papers have been reported in the past ten years on polyaldehydes. ${ }^{4,5}$ However, these polyaldehydes have as yet no practical use because of their extreme thermal instability. They decompose generally to the monomer even at room temperature. During the course of many efforts to solve this problem, it has become apparent that the stability is improved by the capping of the polymer end, ${ }^{6}$ with the addition of basic compounds as stabilizers ${ }^{7-9}$ and by copolymerization with the other monomers. ${ }^{10-15}$ Furthermore, it have been reported that higher aldehydes with such functional groups as halogen ${ }^{12,13}$ cyano, ${ }^{16}$ alkoxy, ${ }^{17}$ and epoxy ${ }^{18}$ polymerize by various ionic catalysts to polyacetals with improved thermal stability.

The present studies were carried out in order to obtain new thermally stable and soluble polyacetals from several aldehydes having a sulfide group as substituent. It was hoped that the effect of the sulfur atom would be to protect the mole- cule from attack by oxygen and acids. It is generally known that by the polymerization of higher aldehydes at low temperature, typical cationic catalysts such as $\mathrm{BF}_{3} \mathrm{OEt}_{2}, \mathrm{AlBr}_{3}$, and $\mathrm{SnBr}_{4}{ }^{\prime}$ give both an amorphous polymer and crystalline polymer. While, in the polymerization of sulfur-containing aldehydes by cationic catalysts, the polymer and the cyclic trimer were obtained in different ratios dependent on the polymerization conditions.

\section{EXPERIMENTAL}

\section{Materials}

(i) Monomers were prepared by the reaction of $\alpha$, $\beta$-unsaturated aldehydes with thiol in the presence of basic catalysts according to the following equation

$$
\mathrm{RSH}+\mathrm{R}^{\prime} \mathrm{CH}=\mathrm{CHCHO} \rightarrow \mathrm{RSCH}\left(\mathrm{R}^{\prime}\right) \mathrm{CH}_{2} \mathrm{CHO}
$$

The procedures were modified from the methods shown in the literature. ${ }^{19-21} \beta$-Methylthiopropaldehyde(MTPA) was produced as follows. Methanethiol, generated from $S$-methyl iso- 
thiourea sulphate and $5 \mathrm{~N}$-sodium hydroxide (Org. Synth Coll. Vol. II, p 345) was passed into acrolein containing cupric acetate kept at $20^{\circ} \mathrm{C}$ with stirring. The reaction mixture were distilled and the fraction was collected to give yield $85 \%$ : bp $72-73^{\circ} \mathrm{C}(23 \mathrm{~mm})$. $\quad \beta$-Methylthiobutyraldehyde(MTBA) was prepared from crotonaldehyde and methanethiol in the same method as above: bp $78-79^{\circ} \mathrm{C}(23 \mathrm{~mm})$; yield $62 \%$. $\beta$-Ethylthiopropaldehyde(ETPA) was also prepared by a similar procedure as above, ethanethiol was added dropwise with stirring to a mixture of acrolein and cupric acetate with cooling in ice and then allowed to stand for $3 \mathrm{hr}$ at $20^{\circ} \mathrm{C}$ : bp $75-76^{\circ} \mathrm{C}(15 \mathrm{~mm})$, bp $185^{\circ} \mathrm{C}(760 \mathrm{~mm})$; yield 95\%. $\beta$-Ethylthiobutyraldehyde(ETBA) was obtained by the reaction of crotonaldehyde with ethanethiol using piperidine as catalyst and the same procedure: bp $77.5-78.5^{\circ} \mathrm{C}(15 \mathrm{~mm}), 93^{\circ} \mathrm{C}$ $(24 \mathrm{~mm})$; yield $87 \%$. Crotonaldehyde and thiophenol were mixed at $0^{\circ} \mathrm{C}$, a droplet of piperidene was added and then the mixture kept at room temperature for $12 \mathrm{hr}$. Fractionation of the product gave $\beta$-phenylthiobutyraldehyde(PTBA): bp $115^{\circ} \mathrm{C}(2 \mathrm{~mm})$; yield $65 \%$. Monomers thus produced were twice distilled under nitrogen prior to use. Purity was checked by gas chromatography. The infrared spectra of the monomers are illustrated in Figures 1a and 2a. Absence of isomers, type $\mathrm{R}^{\prime} \mathrm{CH}_{2} \mathrm{CHSRCHO}$, were confirmed by their NMR spectral examination.

(ii) Solvents were dried by the usual method and distilled.

(iii) Catalysts. Poly(phosphoric acid) and poly(phosphoric acid)_aniline salt were prepared by the same method as shown in the previous paper. ${ }^{22}$ Commercial $\mathrm{BF}_{3} \mathrm{OEt}_{2}$ and $\mathrm{SnCl}_{4}$ were used after distillation. $\mathrm{AlBr}_{3}$ was used without further purification.

\section{Polymerization and Separation of Products}

A typical procedure of polymerization and separation of the products was as follows. Monomer or the monomer solution was placed under nitrogen atmosphere in a polymerization tube ${ }^{15}$ equipped with the attachment for gas inlet and evacuation, previously dried with heating under reduced pressure, and cooled to $-78^{\circ} \mathrm{C}$. After the catalyst solution in toluene was added to the cold monomer solution, the tube was degassed and allowed to stand at the polymerization temperature for $24 \mathrm{hr}$. In the case of the polymerization using poly(phosphoric acid) or poly(phosphoric acid)-aniline salt as catalysts, the monomer solution was added to the cooled catalyst. The polymerization was stopped by the addition of methanol containing a small proportion of pyridine. The polymeric products was separated by adding a large amount of petroleum ether and then filtered, dried, and separated into the ether soluble and insoluble fractions. Furthermore, the latter was fractionated to the soluble and insoluble parts with tetrahydrofuran (THF). The ethyl ether-soluble and the THF-soluble fractions were recovered by adding petroleum ether or water as a precipitant, respectively, to each of the filtered solution. The petroleum ether solution was washed with water, dried over anhydrous sodium sulfate. After removal of the solvents and the unchanged monomer under reduced pressure, the residue was again extracted with petroleum ether. A viscous liquid, which was shown to be the cyclic oligometer by infrared spectra, was isolated by removal of the solvent.

\section{Characterization of the Products}

The viscosity of the polymer solution in THF was measured at $30^{\circ} \mathrm{C}$, using an Ostwald viscometer. Molecular weight of the cyclic oligomer was determined by the cryoscopic method in benzene. Infrared spectra were taken on solutions of polymer in carbon tetrachloride or on film samples prepared from polymer solutions in ether or in THF. NMR spectra of $15-\%$ solutions in carbon tetrachloride of the cyclic oligomer were measured at room temperature.

\section{RESULTS AND DISCUSSION}

\section{Polymerization with Poly(phosphoric acid) Systems and with $\mathrm{BF}_{3} \mathrm{OEt}_{2}$}

The results of the polymerizations are summarized in Tables I and II. Examples of infrared spectra of the products are given in Figures $1 \mathrm{~b}$ and $2 \mathrm{~b}$. In all cases, no solid polymer was isolated, but only viscous liquids were recovered from the petroleum ether-soluble fractions. These compounds were shown to be the cyclic oligomer on the basis of the absence of absorption bands 


\section{N. Yамамото and I. YамаShita}

Table I. Polymerization of sulfur-containing aldehydes by poly(phosphoric acid) catalyst system $^{\mathrm{a}}$

\begin{tabular}{cccc}
\hline Monomer & $\begin{array}{c}\text { Catalyst, } \\
\text { g }\end{array}$ & $\begin{array}{c}\text { Polymeriza- } \\
\text { tion time, } \\
\text { day }\end{array}$ & $\begin{array}{c}\text { cyclic } \\
\text { trimer } \\
\text { yield, } \%\end{array}$ \\
\hline MTPA & PPA 0.25 & 7 & 11 \\
" & PPA·A 0.5 & 3 & 33 \\
ETPA & PPA 0.25 & 7 & 15 \\
I" & PPA·A 0.5 & 3 & 26 \\
MTBA & PPA.A 0.5 & 7 & 8 \\
ETBA & PPA 0.25 & 7 & 3 \\
" & PPA·A 0.5 & 3 & 51 \\
PTBA & PPA 0.25 & 7 & 0 \\
" & PPA.A 0.5 & 7 & 0
\end{tabular}

a Monomer, $0.05 \mathrm{~mol}$; in bulk; temp, $-78^{\circ} \mathrm{C}$.

b PPA, poly(phosphoric acid); PPA.A, poly(phosphoric acid)-aniline salt.

corresponding to hydroxy and carbonyl groups in their infrared spectra. In each cases, the molecular weight measured on the products corresponded to the theoretical value of the cyclic trimer, 2,4,6-trisubstituted 1,3,5-trioxane. The elemental analysis showed good agreement with the calculated value of the cylic trimers. Accordingly, it is obvious that sulfur atoms in side chain were entirely unchanged in the course of the polymerization and separation. In the case of acetaldehyde, formation of cyclic tetramer, metaldehyde, in the presence of cationic catalysts, is well known. Furthermore, in the polymerization of trioxane by $\mathrm{SnCl}_{4}$, the isolation of tetraoxane and pentoxane has been reported. ${ }^{23}$ In the present cases, attempts to separate the cyclic tetramer by column chromatography were unsuccessful. Other possible by-product, aldol, was not detected by IR analysis. It is very interesting that poly(phosphoric acid)-aniline salt which gives selectively the amorphous atactic polymers in the polymerization of the ordinary higher aldehydes, ${ }^{22}$ yieldonly the cyclic trimer in the polymerization of these monomers. It is also noteworthy that $\mathrm{BF}_{3} \mathrm{OEt}_{2}$ equally produces only the cyclic trimer, although this catalyst was fairly effective in the stereospecific polymerization of higher aldehydes having more than three carbon atoms. ${ }^{3}$

\section{Polymerization with $\mathrm{SnCl}_{4}$}

The results of polymerization with $\mathrm{SnCl}_{4}$ as catalyst are shown in Table III. Examples of infrared spectra of polymers are shown in Figures 1c and 2c. The polymerization of PTBA and MTPA, in bulk, in toluene or in $\mathrm{CH}_{2} \mathrm{Cl}_{2}$ gave similar results. In all cases, both the petroleum ether-soluble cyclic trimer and insoluble polymers were isolated. PolyMTPA was a white powder which was sparingly soluble in the usual organic solvents. PolyPTBA was a white resinous material which was only partially soluble in most ordinary organic solvents. Results of fractionation of the polymers with ethyl ether and with THF, successively, are given in Table IV. It is obvious that the structure of these polymers corresponded to polyacetal by infrared spectra, in which very strong absorption bands attributable to ether linkages were observed. The band of carbonyl double bond at $1720 \mathrm{~cm}^{-1}$ in monomer was not seen in the spectrum of the polymer. In the bulk polymerization of ETBA, the petroleum ether-soluble oligomer as well as the ethersoluble polymer $\left([\eta]=0.31\right.$, in $\mathrm{THF}$ at $\left.30^{\circ} \mathrm{C}\right)$ were obtained. Although these oligomers were shown

Table II. Polymerization of sulfur-containing aldehydes by $\mathrm{BF}_{3} \mathrm{OEt}_{2}{ }^{\mathrm{a}}$

\begin{tabular}{|c|c|c|c|c|c|c|c|c|c|}
\hline \multirow{3}{*}{$\begin{array}{c}\text { Mono- } \\
\text { mer }\end{array}$} & \multirow{3}{*}{$\begin{array}{c}\text { Cyclic } \\
\text { trimer } \\
\text { yield, \% }\end{array}$} & & & \multicolumn{6}{|c|}{ Elemental analysis, $\%$} \\
\hline & & \multicolumn{2}{|c|}{ Mol wt } & \multicolumn{2}{|c|}{$\mathrm{C}$} & \multicolumn{2}{|c|}{$\mathrm{H}$} & \multicolumn{2}{|c|}{$\mathbf{S}$} \\
\hline & & Found & Calcd & Found & Calcd & Found & Calcd & Found & Calcd \\
\hline MTPA & 35 & 312 & 312.5 & 46.25 & 46.11 & 7.88 & 7.74 & 30.87 & 30.77 \\
\hline ETPA & 68 & 342 & 354.6 & 50.90 & 50.81 & 8.34 & 8.53 & 27.37 & 27.13 \\
\hline MTBA & 33 & 354 & 354.6 & 50.85 & 50.81 & 8.67 & 8.53 & 27.24 & 27.13 \\
\hline ETBA & 55 & 401 & 396.4 & 54.29 & 54.50 & 9.42 & 9.15 & 24.35 & 24.27 \\
\hline PTBA & 65 & 536 & 540.8 & 66.34 & 66.62 & 6.54 & 6.70 & 18.40 & 17.78 \\
\hline
\end{tabular}

a Monomer, $0.05 \mathrm{~mol}$; catalyst, $0.005 \mathrm{~mol}$; temp, $-78^{\circ} \mathrm{C}$; time, $72 \mathrm{hr}$. 
Table III. Results of polymerization using $\mathrm{SnCl}_{4}$ as catalysta

\begin{tabular}{|c|c|c|c|c|}
\hline $\begin{array}{l}\text { Mono- } \\
\text { mer }\end{array}$ & Solvent & $\begin{array}{l}\text { Polymer- } \\
\text { ization } \\
\text { time, day }\end{array}$ & $\begin{array}{c}\text { Cyclic } \\
\text { trimer } \\
\text { yield, \% }\end{array}$ & $\begin{array}{l}\text { Polymer } \\
\text { yield, \% }\end{array}$ \\
\hline MTPA & Bulk & 1 & 2 & 10 \\
\hline "I & Toluene & 3 & 15 & 19 \\
\hline "I & $\mathrm{CH}_{2} \mathrm{Cl}_{2}$ & 4 & 19 & 23 \\
\hline ETPA & Bulk & 3 & 43 & 5 \\
\hline " & Toluene & 1 & 52 & 2 \\
\hline MTBA & Bulk & 3 & 22 & 0 \\
\hline "I & Toluene & 4 & 25 & 0 \\
\hline ETBA & Bulk & 3 & $48^{b}$ & 32 \\
\hline " & Toluene & 1 & $6^{b}$ & 24 \\
\hline "I & $\mathrm{CH}_{2} \mathrm{Cl}_{2}$ & 3 & 12 & Trace \\
\hline PTBA & Bulk & 1 & 3 & 22 \\
\hline " & Toluene & 3 & 2 & 62 \\
\hline " & $\mathrm{CH}_{2} \mathrm{Cl}_{2}$ & 4 & 9 & 38 \\
\hline
\end{tabular}

a Monomer, $0.05 \mathrm{~mol}$; catalyst, $0.0005 \mathrm{~mol}$; temp, $-78^{\circ} \mathrm{C}$; solvent, toluene $12 \mathrm{ml}$ and methylene dichloride $10 \mathrm{ml}$.

b Cyclic trimer + linear oligomer.

Table IV. Fractionation of polymers obtained by $\mathrm{SnCl}_{4}$ in toluene

\begin{tabular}{|c|c|c|c|c|c|}
\hline \multirow{2}{*}{ Polymer } & \multicolumn{2}{|c|}{ Ether-sol } & \multicolumn{2}{|c|}{$\begin{array}{l}\text { Ether-insol } \\
\text { THF-sol }\end{array}$} & \multirow{2}{*}{$\begin{array}{c}\text { THF- } \\
\text { insol, } \\
\%^{\mathrm{a}}\end{array}$} \\
\hline & $\% \%^{a}$ & $\begin{array}{c}{[\eta]} \\
\mathrm{d} l / \mathrm{g}^{\mathrm{b}}\end{array}$ & $\%^{a}$ & $\begin{array}{c}{[\eta]} \\
\mathrm{d} l / \mathrm{g}^{\mathrm{b}}\end{array}$ & \\
\hline PolyMTPA & 5 & 0.21 & 42 & 0.5 & 55 \\
\hline PolyETPA & 100 & 1.5 & 0 & & 0 \\
\hline PolyETBA & 100 & 0.51 & 0 & & 0 \\
\hline PolyPTBA & 35 & 0.3 & 36 & 0.9 & 29 \\
\hline
\end{tabular}

a Percent to total polymer.

b In $\mathrm{THF}$, at $30^{\circ} \mathrm{C}$.

to be mixtures of the cyclic trimer and the linear oligomer by infrared analysis and by viscosity measurements $([\eta]=0.07)$, attempts to separate them with solvents were unsuccessful. Polymerization in toluene gave similar results to the bulk polymerization. On the other hand, polymerization in $\mathrm{CH}_{2} \mathrm{Cl}_{2}$ gives only the cyclic trimer. The PolyETBAs were white masses which were also found to be polyacetal by their infrared spectra. They are soluble in toluene, ether, THF, and carbon tetrachloride. In the case of the polymerization of ETPA, a large amount of the cyclic trimer was the predominant product in all the experiments. MTBA gave no linear

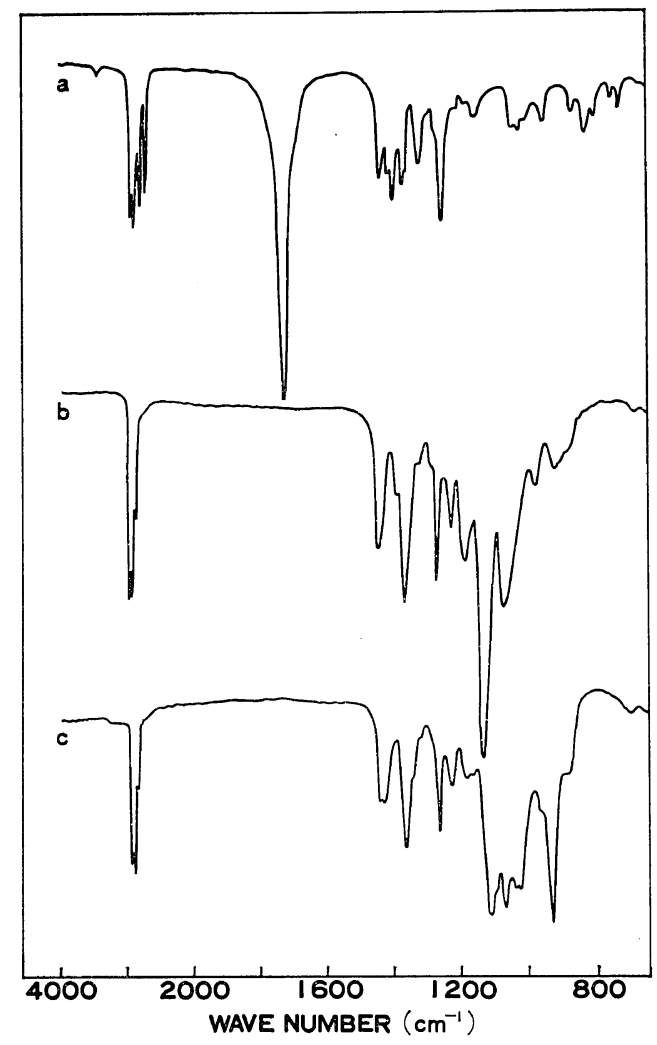

Figure 1. Infrared spectra of (a) ETPA (neat), (b) cyclic trimer of ETPA (in carbon tetrachloride), and (c) polyETPA.

polymer under the same condition.

Polymerization by $\mathrm{AlBr}_{3}$

The results of polymerization using a $\mathrm{AlBr}_{3}$ as catalyst are shown in Table V. Polymerization of MTPA, of PTBA and of MTBA, gave similar results to those obtained in the polymerization using $\mathrm{SnCl}_{4}$ as catalyst.

In bulk and in toluene, ETBA and ETPA gave polymers of higher degree of polymerization than those obtained with $\mathrm{SnCl}_{4}$, in good yields. PolyETPA and polyETBA produced in the polymerization in toluene were partly soluble in ethyl ether, but completely soluble in THF, while those obtained in bulk were easily soluble in ethyl ether. The THF-soluble fraction, however, gave an identical infrared spectrum to that of the completely ether-soluble polymers prepared with $\mathrm{SnCl}_{4}$ as catalyst. Hence, the difference in solubilities may be due to differences of the 


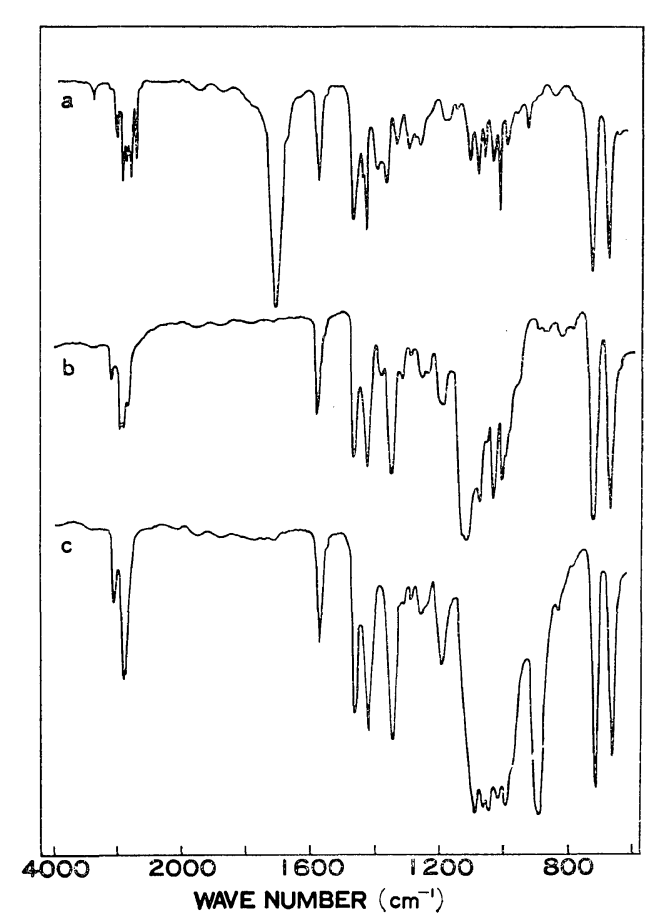

Figure 2. Infrared spectra of (a) PTBA (neat), (b) cyclic trimer of PTBA (in carbon tetrachloride), and (c) polyPTBA (film, THF-soluble fraction).

Table V. Polymerization using $\mathrm{AlBr}_{3}$ as catalysta

\begin{tabular}{|c|c|c|c|c|}
\hline $\begin{array}{l}\text { Mono- } \\
\text { mer }\end{array}$ & Solvent & $\begin{array}{l}\text { Polymer- } \\
\text { ization } \\
\text { time, day }\end{array}$ & $\begin{array}{c}\text { Cyclic } \\
\text { trimer } \\
\text { yield, } \%\end{array}$ & $\begin{array}{l}\text { Polymer } \\
\text { yield, \% }\end{array}$ \\
\hline MTPA & Toluene & 4 & 36 & $29^{c}$ \\
\hline ETPA & Bulk & 2 & 35 & 28 \\
\hline " & Toluene & 4 & 63 & 8 \\
\hline " & $\mathrm{CH}_{2} \mathrm{Cl}_{2}$ & 3 & 53 & $8^{f}$ \\
\hline MTBA & Bulk & 3 & 17 & 0 \\
\hline " & Toluene & 4 & 22 & 0 \\
\hline$" \prime$ & $\mathrm{CH}_{2} \mathrm{Cl}_{2}$ & 3 & 13 & 0 \\
\hline ETBA & Bulk & 3 & $20^{b}$ & 21 \\
\hline " & Toluene & 4 & $18^{b}$ & $56^{e}$ \\
\hline "I & $\mathrm{CH}_{2} \mathrm{Cl}_{2}$ & 3 & 30 & Trace \\
\hline PTBA & Toluene & 3 & Trace & $26^{d}$ \\
\hline
\end{tabular}

a Monomer, $0.05 \mathrm{~mol}$; catalyst, $0.0005 \mathrm{~mol}$; solvent, $12 \mathrm{ml}$; temp, $-78^{\circ} \mathrm{C}$.

b Cyclic trimer + linear oligomer.

c Ether-soluble part, 28\%; ether-insoluble part, $72 \%$.

d Ether-soluble part, 19\%; ether-insoluble part, $81 \%$.

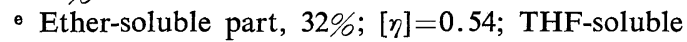
part, $68 \% ;[\eta]=2.22$.

f $[\eta]=1.91$. degree of polymerization. PolyETPA was a white powder, also soluble in chlorinated hydrocarbons and toluene. In $\mathrm{CH}_{2} \mathrm{Cl}_{2}$, ETPA as well as ETBA convert exclusively to the cyclic trimer.

\section{Stereoisomers of the Cyclic Trimer}

In general, the refractive index of the trimers obtained showed a different values according to the polymerization condition, catalyst, solvent, and polymerization temperature. Therefore, the fractionation by liquid-liquid elution chromatography was tried using active alumina as column. The trimer samples were eluted with petroleum ether and with ethyl ether, successively. The NMR spectra of both elution fractions differed from each other, although they gave similar infrared spectra. That is, in the spectra of the parts eluted with petroleum ether a set of triplet based on methine protons of back bone trioxane ring at $5 \mathrm{ppm}$ region were observed, while in the one of the parts eluted with ethyl ether two sets of triplet appeared. From these observation, it was concluded that the former is the all cis isomer, which contains one kind of methine proton, axial proton, in back bone ring (trioxane ring) and the latter has two kinds of methine protons, equatrial and axial, being the cis-trans - cis isomer. It was found that the cyclic trimers of MTPA, MTBA and ETPA contain both isomers, while ETBA contains only the all cis isomer, regardless of conditions produced. Separation and characterization of the isomers will be described in detail in a separate paper.

Acknowledgement. The authors wish to thank Professor T. Tsuruta of Tokyo University for many helpful discussions.

\section{REFERENCES}

1. O. Vogl, J. Polym. Sci., 46, 261 (1960); Belg. Patent 580553 (1959), Priority US, 8/18/58.

2. J. Furukawa, T. Saegusa, T. Tsuruta, H. Fujii, and T. Tatano, J. Polym. Sci., 36, 546 (1959). J. Furukawa, T. Saegusa, and H. Fujii, Makromol. Chem., 37, 147 (1960).

3. G. Natta, G. Mazzanti, P. Corradini, and I. W. Bassi, ibid., 37, 156 (1960).

4. J. Furukawa and T. Saegusa, "Polymerization of Aldehydes and Oxides," John Wiley and Sons (Interscience Publishers), Inc., New York, N. Y., 1963, pp 77-116 and pp 407-413. 


\section{Cationic Polymerization of Sulfur-Containing Aldehydes}

5. O. Vogl, "Polyaldehyde," Marcel Dekker, Inc., New York, N.Y., 1967, pp 43-64 and pp 77-89.

6. O. Vogl, Chem. Ind., (London), 748 (1961).

7. O. Vog1 and D. Funck (du Pont), U.S. Patent 3001966 (1961).

8. J. Furukawa, T. Saegusa, S. Chen, and H. Imai, Japan Patent Appl. Pub. 19843 (1961).

9. H. D. Hermann, K. Weissermel, and D. Lohaus, Ger. Patent 1131401 (1962).

10. H. Fujii, T. Fujii, T. Saegusa, and J. Furukawa, Makromol. Chem., 63, 147 (1963).

11. H. F. Mark and N. Ogata, J. Polym. Sci., Part A, 1, 3439 (1963).

12. T. Iwata, G. Wasai, T. Saegusa, and J. Furukawa, Makromol. Chem., 77, 229 (1964).

13. T. Iwata, T. Saegusa, H. Fujii, and J. Furukawa, ibid., 97, 49 (1966).

14. H. Takida and K. Noro, Kobunshi Kagaku (Chem. High Polymers), 22, 43 and 473 (1965).

15. A. Tanaka, et al., Kobunshi Kagaku (Chem. High Polymers), 20, 687, and 694 (1963); 22, 216, 220,
317, and 321 (1965);

A. Tanaka, Y. Hozumi, K. Hatada, and R. Fujishige, J. Polym. Sci., Part B, 2, 181 (1964).

16. H. Sumitomo and S. Kobayashi, J. Polym. Sci., Part A-1, 4, 907 (1966).

17. H. Takida and K. Noro, Kobunshi Kagaku (Chem. High Polymers), 20, 712 (1963).

18. W. J. Sullivan, U. S. Patent 3067174 (1962); J. Furukawa and T. Saegusa, Pure and Applied Chem., 4, 387 (1962).

19. J. R. Catch, A. H. Cook, A. R. Graham, and I. Heilbron, Nature, 159, 578 (1947).

20. E. Pierson, M. Giella, and M. Tishler, J. Amer. Chem. Soc., 70, 1450 (1948).

21. R. H. Hall and D. K. Howe, J. Chem. Soc., 2723 (1949).

22. T. Miyakawa and N. Yamamoto, Kogyo Kagaku Zasshi (J. Chem. Soc. Japan, Ind. Chem. Sect.), 65, 390 (1962).

23. T. Miki, T. Higashimura, and S. Okamura, $J$. Polym. Sci., Part A-1, 5, 95 (1967). 